\title{
Systemic Creativities in Sustainability and Social Innovation Education
}

\section{José-Rodrigo Córdoba-Pachón ${ }^{1}$ (D) - Francesca Mapelli ${ }^{2} \cdot$ Farah Nabil Adel Al Taji $^{2}$. Diana M Donovan ${ }^{3}$}

Published online: 30 May 2020

(C) The Author(s) 2020

\begin{abstract}
The aim of this paper is to aid educators in sustainability or social innovation to make sense of their creativity. We use a systems model of creativity (Csikszentmihalyi 1988, 1996, 1999) as an enquiring device to tease out issues that influence creativity within these realms. Data from semi-structured interviews with senior and junior educators in two geographical locations lead us to elaborate two systems models to reflect creativity. These models portray creativity as emerging from the alignment of and connections between creators, domains and field elements as suggested by Csikszentmihalyi. However, we also identify some intermediary or absent connections between the model elements which deserve further attention, as their uncritical pursuit could potentially exacerbate exclusion or marginalisation of junior educators' personal values and interests. Therefore, critically and creatively informed learning could be better cultivated in these realms. This and other insights could have important implications for how creativity and its nurturing in education could be advanced in the long run.
\end{abstract}

Keywords Sustainability education · Social innovation education · Creativity · Systems thinking · Csikszentmihalyi $\cdot$ Systems models

José-Rodrigo Córdoba-Pachón

j.r.cordoba-pachon@rhul.ac.uk; https://orcid.org/0000-0001-6356-6384

Francesca Mapelli

francesca.mapelli@polimi.it

Farah Nabil Adel Al Taji

farah.al@polimi.it

Diana M Donovan

diana.donovan.2018@ live.rhul.ac.uk

Extended author information available on the last page of the article 


\section{Introduction}

Many educational institutions worldwide are currently promoting sustainability or social innovation as valuable areas of knowledge. As educators in these areas and with different degrees of seniority or experience, we often find ourselves facing daily challenges in response to continuous internal and external demands (Alcaraz and Thiruvattal 2010). These include teaching our students the value of new and changing knowledge compared to traditional or more stable methods (Ghosal 2005). Additionally, we are required to prepare students to learn by 'experiencing' or 'doing', as a way of helping them secure employment whilst developing a sense of responsibility towards their organisations, communities or societies (Wagner 2015; Millar and Price 2018). We are to be innovative in our teaching methods to clearly show students the conceptual and practical values of what they are learning (Dieleman and Huisingh 2006).

To address the above issues, in this paper we adopt a view of creativity as a systemic phenomenon (Barron 1968; Amabile 1983; Csikszentmihalyi 1988; Montuori and Purser 1995; Glavenau 2010; Glavenau et al. 2019; Córdoba-Pachón 2019). This means that creativity emerges as the by-product of knowledge interactions between creators and other relevant individuals or groups. We use a systems model of creativity proposed by Csikszentmihalyi $(1988,1996,1999)$ to identify and enquire into the activities, relationships and emerging issues that (could) be influencing, or influenced by, educators of sustainability or social innovation.

Our interpretations and findings from conducting several interviews with senior (having more than 5 yrs' experience of teaching and research; hereafter referred to as "seniors") and junior educators (having less than that; "juniors") in two different geographical contexts lead us to elaborate different systems models for creativity. As a result, we conceive of creativity as gradually emerging from the interactions between creators (educators), domains and fields of knowledge related to sustainability or social innovation. However, we also identify some intermediary, absent connections between the models' elements which deserve further attention. Their uncritical pursuit could potentially exacerbate exclusion or marginalisation of less experienced (i.e. junior) educators' personal values and interests, to their detriment and that of education in these areas in the long term. This and other insights could have important implications for the study and promoting of creativity in education.

\section{Sustainability and Social Innovation}

After their initial 'boom' or 'novelty' in education and under the different labels: Sustainable Development, Social Enterprising, Sustainability, Social Innovation (Moon and Matten 2004; Pol and Ville 2009), sustainability and social innovation have become key education areas worldwide. Knowledge of these areas could help students and educators develop critical awareness, skills and knowledge of impacts of organisational or managerial activity in the wider sphere of society and worldwide (Dieleman and Huisingh 2006; Domask 2007; Reason 2007; Alcaraz and Thiruvattal 2010; Gitsham 2012; Kurucz et al. 2013; Zorio-Grima 2018).

However, there are several challenges for educators in these areas (Lozano 2006; Brower 2011; Smith and Woodworth 2012; Aragon-Correa et al. 2017; Zorio-Grima 2018). Among them, educators need to continuously: i) ensure the physical (public status, prestige) and online visibility of their efforts and initiatives (Zorio-Grima 2018); ii) secure financial or educational resources needed to develop innovative learning activities (Lozano 2006; Brower 2011; Smith 
and Woodworth 2012; Tomkins and Ulus 2016); and iii) identify and work with champions (individuals, groups) across institutional departments to persuade others of the value of their work (Lozano 2006).

Furthermore, educators need to pose and address learning questions for which there are no straightforward answers let alone defined problems (Csikszentmihalyi 1996; Craft 2001). Existing theories and models of management education need to be challenged (Ghosal 2005) whilst educators keep abreast of their interests or career prospects and those of their students (Wagner 2015). There is a need for educators to generate novel, valuable and implementable ideas, processes or practices in research or learning/teaching. We are to manage ambiguity and uncertainty, take significantly important risks or follow our inner motivations or life purpose(s) (Wagner 2015; Amabile 1983; Amabile 1998).

As an emerging trend worldwide in the field, creativity is not considered a property of individuals but rather a systemic phenomenon. This means that creativity emerges in the interaction between creators and their relevant audiences (Barron 1968; Amabile 1983, 1998; Csikszentmihalyi 1988; Montuori and Purser 1995; Sawyer 2006; Glavenau 2010; Glavenau et al. 2019; Córdoba-Pachón 2019). Csikszentmihalyi (1988, 1996, 1999) proposes a generic systems model of creativity comprising three elements, whose interactions reflect and generate what are socially and culturally accepted as creative contributions at a given time (Figure 1).

In Csikszentmihalyi's model of creativity, creators' ideas and activities are shaped by domains and fields of knowledge. Domains of knowledge refer to sets of memes or items of information that individuals build on and create and which are adopted. Through protracted and lengthy efforts, creators learn to manipulate these memes and generate novelty in the form of new or updated memes.

The attribution of novelty is what society and culture consider relevant at a moment in time. Such attribution is given by fields of knowledge or groups of individuals who can alter the structures of knowledge domains and influence or be influenced by creators' work. Fields are conceived of as individuals or groups of 'gatekeepers', 'sponsors' or 'advocates' who select

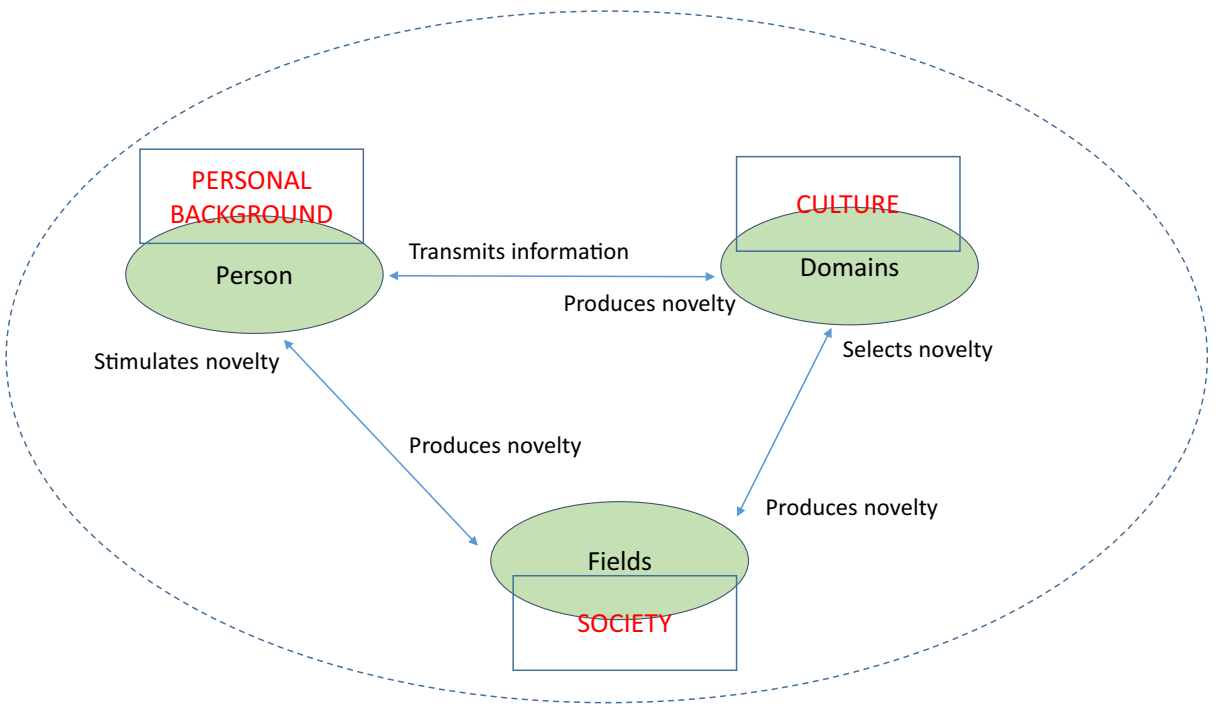

Fig.1 A systems model of creativity (Csikszentmihalyi 1988) 
what counts as 'novel' in a domain of knowledge (i.e. by judging, funding or commissioning creators' work) and support (sponsor, advocate, fund) it.

A simple example of this model in practice could be that of writing an academic paper or a textbook. Authors (creators) learn the symbols or memes used in a specific domain of knowledge and generate a novel contribution that is then assessed by journals/book editors or reviewers, other educators or educational managers (the field) as such. Contributions can then be accepted and incorporated into the respective domain(s) of knowledge for future use by others in research, education or practice. In the whole process, there is continuous interaction between authors, colleagues, editors or reviewers that contribute to shape up what will finally emerge as a published, legitimate, creative output.

The model's perceived analytical focus on eminent or 'big' or 'eminent' creativity has been a source of criticism, as other and more mundane, daily life manifestations of creativity have been identified in the creativity field (Craft 2001; Kaufman and Beghetto 2009; Hanson 2013; Córdoba-Pachón 2019). Furthermore, the gradual unfolding of creativity might not fully align with macro, protracted processes of differentiation or integration of knowledge as Csikszentmihalyi (1988) suggests. In this regard, the model could consider in more detail how less 'gifted' individuals deal in their daily lives with tensions and dilemmas when pursuing creative efforts, so that their attempts or 'failures' could also be critically included as part of creative processes or activities (Hanson 2013).

In this paper we use Csikszentmihalyi's model as an enquiring, interpretive lens to study phenomena of creativity in sustainability and social innovation education. We focus our analysis on educators in these areas, their immediate relationships with other individuals or groups of people. This will help us form an overall sense of how their creativity emerges, what/ who influences/hinders or what/who is influenced or hindered by them, and what could be done to improve their current situation.

\section{Methodology}

\section{Case Studies Selection}

We carried out two case studies in two different geographical contexts (Eisenhardt 1989; Yin 1994). These are to be named PM and UNU respectively. We selected institutions that have developed education and research in sustainability or social innovation for several years, and which are internationally recognised, attracting students and academics from different parts of the world. The choice of these as case studies also follows our intention to have a representative sample of the dynamics of education and with two different experiences, as well as to have adequately traceable/defensible sources of data and insights.

The first case, PM, is drawn from a technical university founded in 1863. It has fivecampuses including its headquarters. There are more than 40,000 students across the three main teaching and research areas hosted by the university, namely architecture, design and engineering. Our case is based on education at the Department of Management, Economics \& Industrial Engineering, as it hosts research and teaching activities related to both social innovation and sustainability. The case builds on experiences of a group of educators and researchers which delivers education mainly in social innovation and other subsidiary areas including economic sustainability, social investment, social impact measurement and social growth. 
The second case, UNU, is drawn from a university founded in the mid nineteenth century. Initially established as a women's college, it has undergone a series of transformations including the appointment of the first female professor, the merging with another college, and the setting up of a liberal arts driven school of management in the 1990s. Currently this institution hosts more than 9000 students in both undergraduate and postgraduate levels. Sustainability education is delivered through different programmes at these levels and mainly at the management and geography schools. We focus our case study on the School of (Business and) Management. Alongside the introduction of courses and programme options in sustainability at different levels, UNU has also adopted the Principles for Responsible Management Education or PRME and has joined associations like EABIS (European Academy of Business in Society). Among other activities, an annual PRME report is prepared and submitted annually with contributions from educators who are also invited to attend EABIS events.

We recruited educators from each case whom we considered had different roles (teaching, research or any other form of leadership) as well as diverse backgrounds and education experience. We were particularly keen on having a balanced mix of senior (more than 5 yrs of experience in research and teaching) and junior educators (less than that), to be able to identify potential differences in their perceptions. With those who initially responded positively we employed a "snowball sampling" technique (Rubin and Babbie 1993; Sheu et al. 2008) to identify other educators which we could reach. Overall, we recruited thirteen (13) participants as reported in Table 1.

\section{Collection of Data}

We built and analysed the above cases using three main strategies: 1) Designing and conducting a series of semi-structured interviews with educators in UNU and PM; 2) Drawing and presenting a rich picture and systems model for each of the cases with information collected through the interviews (Checkland 1981); and 3) Iterating over the above data in order to reduce potential biases (Eisenhardt 1989) and help us generate further insights as to how educators' creativities could be better understood and nurtured.

The interview questions were focused on three different sections/stages for an educator, namely "becoming", "acting", and "being" (see appendix 1). The "becoming" section is

Table 1 List of interviewees for our study

\begin{tabular}{lll}
\hline Case & Interviewee & Role of the interviewee \\
\hline UNU & D.P. & Junior educator \\
& H.T. & Senior educator \\
& L.R. & Senior educator \\
& N.V. & Junior educator \\
& S.W. & Senior educator \\
PM & S.A. & Senior educator \\
& F.A. & Junior educator \\
& M.C. & Senior educator \\
& M.P. & Junior educator \\
& R.L. & Junior educator \\
& D.C. & Junior educator \\
& R.R. & Senior educator \\
& I.B. & Senior educator
\end{tabular}


specifically relevant for the framework in which creativity emerges as a long and protracted effort as suggested by Csikszentmihalyi's model. Within this section, we asked interviewees questions concerning how education has become important for them, and what issues or circumstances have influenced this process. We did not provide a specific definition of creativity, and only when asked we talked about the attributes of a creative idea/process/ product: something novel, that is of value to others than the creator, and something that 'works' or can be implemented (Runco and Jaeger 2012; Cropley and Cropley 2016).

The second section/stage dealt with "doing". We were interested to know how creativity is included in educators' daily activity, since creativity also has to do with integrating disparate domains of knowledge, and with interacting with people inside and outside their own field (Csikszentmihalyi 1996). We asked about knowledge, tools or resources used by educators within and beyond their institutions to develop educational activities.

Finally, the "being" section aimed to investigate how educators perceived themselves as being or having become 'different' from others. We asked how their activity has contributed to making them different from others (other educators, students, external individuals), and if or how such differences could relate to their values, research or teaching interests.

The interview protocol and questions were finalised via some pilot interviews. Subsequently, all the interviews were carried out, with an average duration of half an hour and one (1) hour. Consent to use the contents of interviews was obtained prior to conducting each of them. Interviews were recorded and interviewers took notes during and immediately after.

\section{Development and Validation of Rich Pictures and Systems Models}

We clarified and validated the content of the interviews by drawing rich pictures of each of our cases. The Rich Picture has its origins in soft systems methodology or SSM (Checkland 1981; Stanton and Mcllroy 2012). It is a representation or expression technique whose main purpose is to provide a comprehensive description of a situation to help its actors make sense of and learn about it as perceived by themselves and others. Rich pictures are recognized to be particularly interesting to provide easily interpretable and preliminary depictions of complex systems or situations (Checkland 1981). The description provided by rich pictures is inherently flexible, thus allowing researchers to iterate and integrate information from a variety of sources (Monk and Howard 1998; Stanton and McIlroy 2012), as well as gain a broader view of a situation.

With the content and insights obtained by discussing the rich pictures among ourselves and with the cases' participants, and using Csikszentmihalyi's model as a template, we formulated several systems models of creativity. According to Checkland (1981), systems models would allow a comparison of how things could work versus how they currently work, enabling us as researchers to formulate and discuss possibilities to improve a situation as perceived by participants.

In the following section of the paper the two case studies are presented together with their rich pictures and systems models. We then discuss the resulting insights and formulate some implications for the future improvement of creativity in education in the realms explored.

\section{PM Case: 'It is complicated'}

The authors started by building the case of PM university. While doing that, a feature that all of us noticed from the interviews was the high degree of 'complicatedness' perceived by PM 
educators. Indeed, this is a feature that clearly emerged from all the interviews we carried out, and several drivers for that can be recognized. First, multiple intersections among the different players can be identified, thus increasing the presence of multi-level relations. Second, all the interviewees mentioned that they have been collaborating with other individuals and organisations, several of whom are external to their educational institution (Figure 2).

The rich picture speaks about how, in the PM case, the presence of many interactions between people generates a 'space' for creativity. In the following, some evidence from the PM case is presented, thus highlighting how this space for creativity is generated and the intersections among creators.

First, where there was no clear (although favourable) organisational structure or allocation of responsibilities, both senior and junior educators have had the opportunity to bring their unique ideas and contributions to create this space. An example of this is the process that led to the creation and the growth of a particular MSc course related to social innovation. This course has been developed under the stimulus of senior educators (i.e., full and associate researchers) in collaboration with post-doctoral research fellows and $\mathrm{PhD}$ candidates). At the beginning of the social innovation initiative at the institution, senior educators could bring their own contribution in the first phases of the design of courses, when they had to give the main direction and position the course within the faculty offer. The novelty of the course and a research funding track record in social innovation also allowed them to use innovative teaching methods and co-design and co-deliver it with outside organisations, for instance, involving students in identifying societal challenges, and addressing them in collaborative and sponsored projects with social innovation organisations in field work. Several PM educators mentioned this:

"We decided to use some new tools to approach creating an exercise with students, and we tried to focus a little bit on what we were trying to research. So, proposing some topics for projects that come from our experience and our interest." - M.P.

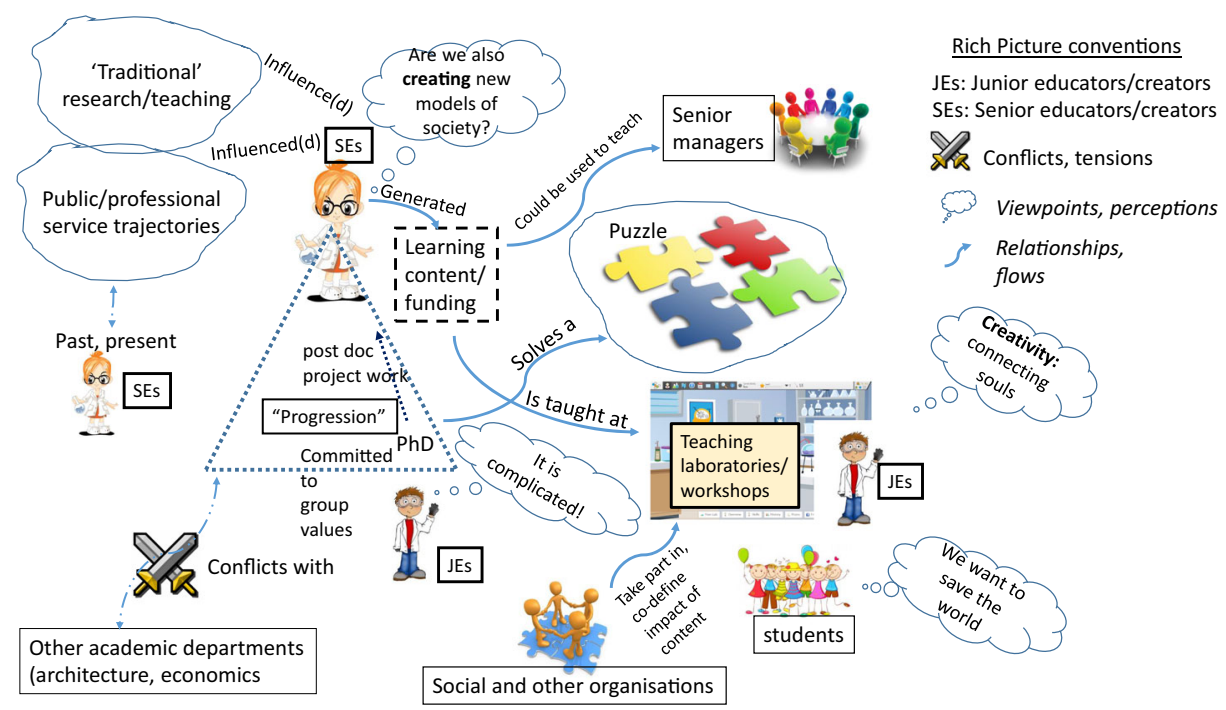

Fig. 2 A rich picture of social innovation education at PM 
"This [the new MSc programme] was designed to be the honour programme for multidisciplinary education...the idea was [initially] a bit vague, but [we argued that] it was our engineering, architecture and industrial design students who should have been exposed to additional content not necessarily related to their field of study to improve their preparation." - M.C. (brackets added).

"We asked people about their city and places where they lived, and we tried to find projects based on societal problems experienced by these people. Culturally it was the first time in the history of Italian policy making that we financed, not supply-side research, but for the first time we used the problems as the fundamental units for action. We wanted to boost multi-disciplinarity and problem solving." - M.C.

Secondly, since courses in social innovation were completely missing in the MSc offer, senior PM educators found an opportunity by moving from their 'old' institutions or careers. They connected with academic and professional peers and mentors with whom they could discuss and enhance their initial ideas. Through time, some of these connections became educators themselves. As a result, junior educators ( $\mathrm{PhD}$ students, tutors) and students found a 'space' where they are stimulated to help advance the curriculum and benefit from this.

A key connecting element for creativity is what educators call 'the learning lab'. This is a series of activities that are complementary to normal lectures. Students work in project groups to address needs that have been identified and presented by external stakeholders (non-governmental organisations, social enterprises). Through the course of a semester and with the support of junior educators, groups work to develop solutions which are then presented to relevant stakeholders. The high exposure to real situations gives both junior educators and students opportunities to learn by experience. This form of learning stimulates the creativity of juniors by designing ways (i.e. the spaghetti challenge, an experience to build something together) to help students gain and practice their soft (communication and presentation) skills. At the same time such degree of exposure contributes to intensify the perceived complicatedness of PM, leading juniors to adopt hybrid profiles, in other words, becoming educators, researchers and managers at the same time, whilst connecting their values with their work.

These and other insights from the rich picture allow us to generate a systems model of creativity for PM as portrayed in Fig. 3. This model shows how senior and junior educators act as brokers between domains and fields of knowledge, as they are asked to build new social impact measurement models to be adopted by government organisations and to be further refined by government funding or policy. Also, the 'learning lab' acts as a connecting element between senior (course content) and junior (ideas for improving group work) educators' activities and their passion for social innovation. External stakeholders (experts, government representatives or funders) could be conceived of as belonging to fields of knowledge. Some of them require more practical or accurate methodologies to measure social innovation impact, and therefore influence the creativity of senior and junior educators to develop them.

It is also worth noticing though that in PM, it is mainly senior educators (and not junior) who can lead or build field relationships. On the one hand, it seems to be a natural and resulting behaviour, as high-level relations need to be managed by experienced educators. On the other, junior educators are often prevented from creating their own network with internal or external stakeholders outside the lab, and they are not explicitly allowed to interact directly to generate impact in the field. Their interactions are somehow "filtered", and feedback from this is unclear. 


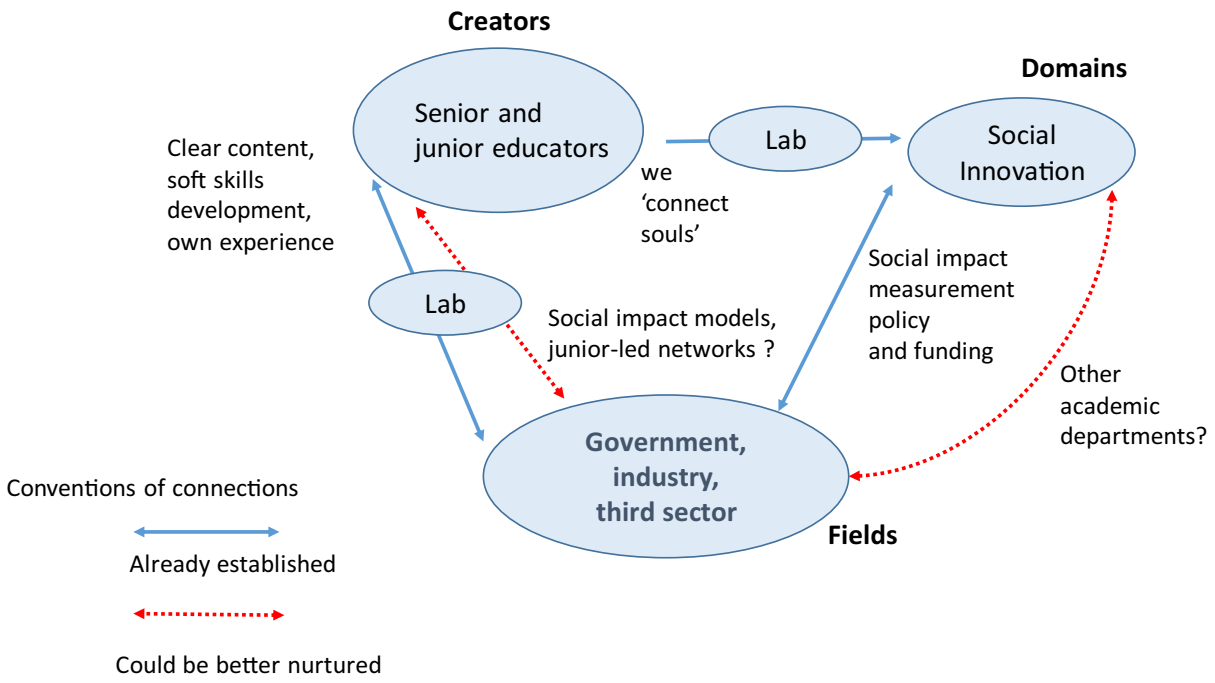

Fig. 3 A systems model of creativity at PM

\section{UNU: A Hub for Sharing}

The UNU case could be briefly described as a hub for sharing. In particular, the idea of a 'sustainability hub' came to us when presenting our pictures, models and findings to UNU participants. Like the PM case, at UNU, several senior educators said that they had also found a 'space' to meet valuable and like-minded peers and mentors to talk about sustainability. They found themselves able to exert their creativity by engaging more directly and innovatively with colleagues and students and collaborating to advance their research agendas (Figure 4).

Furthermore, seniors regard this hub to be 'saving space for their career'. Earlier on and in other institutions they had to bear traditional forms of education in the form of 'lecturing by slides', or extending content in economics, business or accounting to include some 'additional' sustainability considerations or interpretations. This, together with opportunities to work elsewhere and UNU's internationally recognised research reputation contributed to educators' move. In this new (friendly) location, seniors have been able to design and run their own sustainability courses using innovative and experiential methods like games, role playing, or critically designed case studies. They have also been able to pursue their own research agendas: this is often done in collaboration with, or by mentoring or being mentored by, colleagues. As mentioned during our interviews,

"And in the accounting department, I once again had to teach mainstream accounting, but I was lucky enough to develop two courses in the social environment accounting area, stakeholder engagement, and reporting. So, I was teaching undergrad, postgrad and MBA students in those kind of broad areas... So I've always felt like I'm on the fringe of an accounting academic and a management academic, but the common thread from all of it was sustainability... So when I joined UNU, nearly a year ago, when I got a job in sustainability CSR it kind of feels like a match." - H.T. 


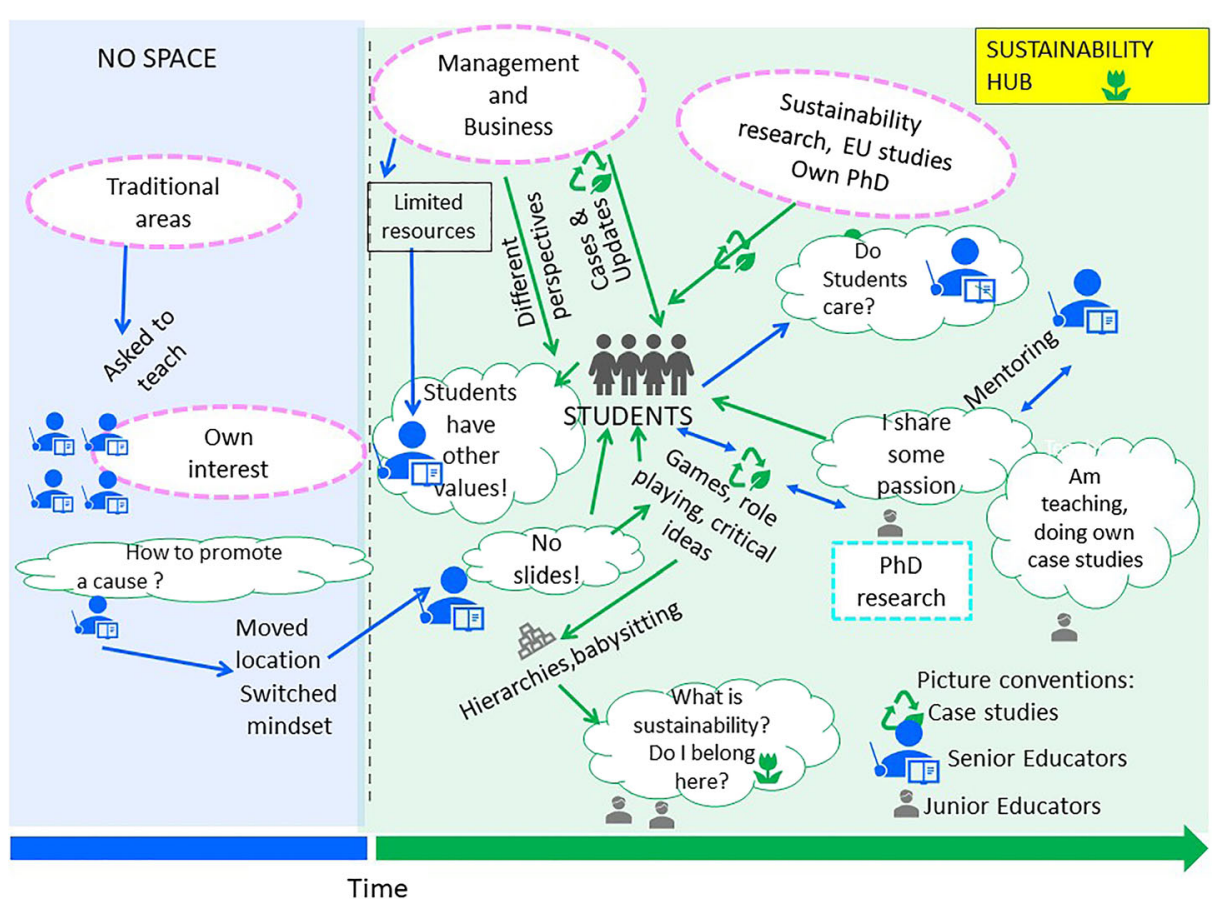

Fig. 4 A rich picture of sustainability education at UNU

"And so, I moved to the UK, and the move to the UK represented a change in all possible respects. I feel part of it, whereas in my former space I felt like an alien, I don't know whether it was freedom of research that is granted here to create this kind of positive home of sorts or something else." - L.R.

At UNU, many junior educators also came to the hub attracted by the reputation of UNU's interdisciplinary research centre. Juniors' creativity has unfolded in two ways: a) in relation to their own $\mathrm{PhD}$ studies and $\mathrm{b}$ ) in helping seniors or mentors to teach by delivering practical workshops in whichthey can present their own research sometimes. Although many of the juniors share the seniors' passion for sustainability, some of their perceptions about the 'saving' nature of the hub in relation to sustainability are mixed:

"As for the preparation in general, I would say that working on seminars I mostly related to what lecturers were telling me, so most of them were quite organized and therefore had a ready topic. Some of them also provided slides, which was the further extreme organization." - D.P.

"I have been at UNU for 3.5 years, started teaching not necessarily sustainability courses but marketing, behaviour, consumer, consumption, advertising and digital marketing." - N.V. 
"I wasn't asked to teach a seminar on sustainability, I was asked to teach a seminar on ethical consumption. In which I spoke about sustainability and I used themes such as resilience which belong to the sustainability world. In this way it is a little bit of stretch to say I was a sustainability educator." - D.P.

Figure 5.

The derived systems model of creativity for UNU in fig 5 shows that senior educators have created or contributed to a 'space' or a 'hub' thanks to their gradually established connections within the field (their research, diverse although limited learning resources, UNU research centre and its reputation). The institutional environment has enabled them to establish or work on sustainability sub-domains of knowledge (e.g. accounting for sustainability, corporate social responsibility, human resource management, consumerism, supply chain management). UNU junior educators participate through the research centre in the established connections made by seniors, but they are also craving more clarity and inclusion.

When presenting the rich picture and systems model to UNU faculties at an away day organised by the sustainability research centre, we highlighted the above connections (established, in need of being better nurtured or clarified). A first reaction from one senior educator did not focus much on what was missing according to the suggested model (i.e. clearer impact in industry or government in fields of knowledge, or better inclusion of juniors); rather, she highlighted the need for us to evidence the unique interdisciplinary nature of the 'hub' in comparison with other higher education institutions, and how the research centre was 'successful' in promoting and managing inter-disciplinary activities.

We took her point on board. We would consider the inclusion of the research centre as a potential intermediary between creativity subdomains of knowledge and fields, as the systems model of figure 5 shows, but also prompted further discussion by asking the question:

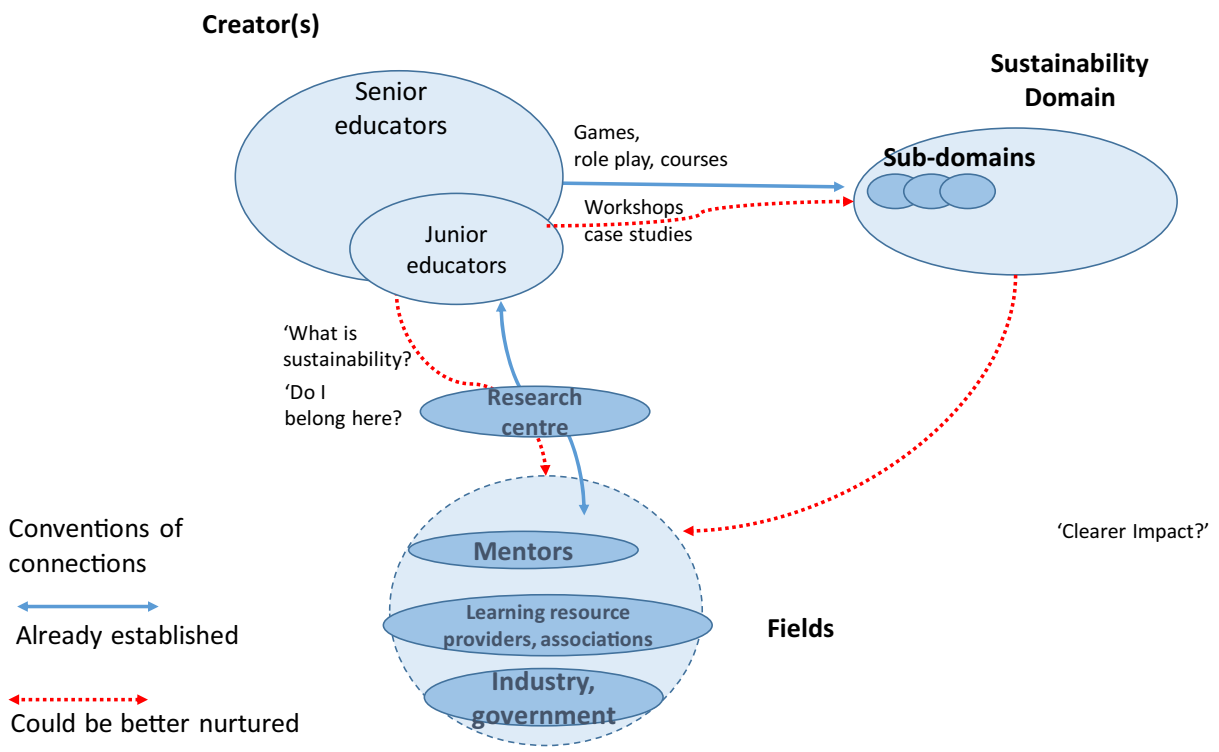

Fig. 5 A systems model of creativity at UNU 
"So what is really stopping 'us' in being more creative?" After some silence from the audience, another senior educator answered, timidly: "Maybe a fear to fail...?"

This reaction suggests that there are ways in which educators' creativity could become more inclusive and empowering. We discuss this and other issues in the next section of the paper.

\section{Discussion}

Overall, our findings show that education in sustainability or social innovation is rich, multifaceted, 'complicated' and with opportunities to further develop. Creativity in these areas has emerged as senior educators moved to friendlier institutional locations and could design and teach courses in innovative (i.e. experiential learning based) ways to establish domains or subdomains of knowledge; they were also able to network or bring like-minded academics, associations, funders, policy makers or hybrid professionals. These in turn have influenced and have been influenced mostly by senior educators' work.

For junior educators, creativity is about joining in or taking part in what goes on in the 'spaces' created by seniors. It is also about helping teach relevant content and devising ways to better support students' learning in lectures, workshops or practical projects, all of this whilst developing their own research and teaching agendas.

Whilst senior educators' creativities seem to align to Csikszentmihalyi's model, there are some additional (or missing) elements whose presence could help juniors feel included or less marginalised, and which could contribute to sustain creativity in these realms in the long term. In line with the findings of Gangadharbatla (2010) and Stierand et al. (2014), our systems models have revealed the presence of intermediary or connecting elements as being potentially conducive to as well as conducing creativity. This is the case of the learning lab at PM and the research centre at UNU. These elements seem to have acted as conduits of knowledge towards and from relevant (sub) domains and fields of knowledge.

Despite the positive role of these elements in gradually aligning education with what goes on elsewhere in societies (Csikszentmihalyi and Wolfe 2000), if uncritically pursued, these intermediaries currently exclude or marginalise other ways of learning about sustainability or social innovation. Their activities could be contributing to reinforce hierarchical power relations between senior and junior educators (Tomkins and Ulus 2016; Burchell et al. 2015; Millar and Price 2018).

Moreover, this potential exclusion or marginalisation of junior educators or other ways of learning can also be legitimised by the systems model itself, if senior educators fail to acknowledge that the connections with fields and domains of knowledge that they have established have not only been the result of their efforts as 'lone' geniuses (Montuori and Purser 1995), but also of participations at different levels of other actors including junior educators and students. A systemic view of creativity invites us to consider how creativity is not the property of our individual or collective actions, but also the actions or inactions of others (students, institutional managers, research centres or learning labs, etc.).

Other ideas about systems thinking and creativity can continue helping us. Experiential learning based forms for education, like the ones identified at PM and UNU (projects, games, role playing, learning labs), could be complemented in three ways. Firstly, rather than being passive to societal values, junior educators and students can be better understood as increasingly driven by their passion, curiosity and a sense of commitment to save our planet 
(Wagner 2015). In terms of the systems model of creativity used in this paper, they could also be considered active members of SE/SI domains and fields of knowledge. With this in mind, seniors could develop appropriate learning environments to help them generate direct and measurable impacts by

a. setting up challenges that align with their curiosity, skills and inner motivations (Csikszentmihalyi 1996; Amabile 1998);

b. mentoring them to pursue efforts that respond to their own sense of purpose in life (Wagner 2015);

c. designing and facilitating activities and conditions that get the best of juniors' (or students)' skills, motivations and knowledge, and

d. developing their creative thinking skills as well as their expertise (Amabile 1998).

Secondly, senior educators could help their junior colleagues and students to 'fail safely' (i.e. when establishing networks or trying new teaching or learning methods), and with a view that failure can contribute to generate a more inclusive and learning culture in which creativity and failure are equally valuable (Hanson 2013; Wagner 2015; Córdoba-Pachón 2020a). Lastly, there is a wealth of techniques which could instil in educators and students the development of new learning approaches. For instance, using systems models, metaphors or analogies to explore local situations; challenging taken for granted assumptions about them; allowing time for unstructured 'play'; building assessment criteria for creative work; instilling tolerance for ambiguity; delaying and diversifying gratification; encouraging collaboration or risk taking (Amabile 1998; Wagner 2015; Sternberg 2010; Cropley and Cropley 2016; Córdoba-Pachón 2011, 2020a).

The above insights suggest that it is important to challenge our current thinking and creativity to develop and sustain education in sustainability and social innovation. It might be time for (senior) educators to 'let go' of what has worked well for all of us in the past. It is the openness to new ways to foster creativity, the curiosity, the directedness/ ambiguity that comes from engaging ourselves, our students and others in continuously exploring the realms of sustainability or social innovation which could help us to sustain our efforts and those of future generations. We should continue being or becoming creative. The hope is that the insights of this paper could inspire other educators to do the same.

\section{Limitations and Future Research}

In our study, we relied on Csikszentmihalyi's $(1988,1996)$ model and research method (interviews) to identify issues and implications for the further development of creativity. We did not directly observe educators crafting their creativities and this could limit the scope of our interpretations or proposals to advance education. More systemically oriented methods of enquiry could be used in this regard.

Furthermore, we did not subject our ideas to long or critically informed debate with our research participants. This is something that could help enrich dialogue between systems perspectives about creativity, and which could be helped by employing power-sensitive participative methods or techniques (Córdoba-Pachón 2020b). This could also help us better understand how experiential learning activities could better work with young educators and students and in more detailed consideration or awareness of their own (power) circumstances. 
For future research, we would like to study in more depth what it is that educators and students in sustainability and social innovation do when thinking about creativity and novelty; what challenges and opportunities they encounter in practice; who they rely on when developing and testing their ideas; and what institutional constraints or opportunities they think of in relation to how education could help them address the challenges encountered now and in the future.

Acknowledgements We would like to thank educators who gave their time for interviews and feedback about our study, and to the reviewers of this paper who provided very useful feedback.

\section{Appendix 1- Interview Questions}

\section{Name}

Background:

- Your position in the university

- How long you have been working for this university

The 'becoming' of sustainability/social innovation education (SE/SI):

- In your view and according to your experience, how is it that Sustainability Education SE or Social Innovation Education (SI) has become a space or set of spaces of education, learning and research (academic, practical)? What drivers, pressures, policies have influenced it?

- Globally?

- In the country where you are now working?

Your 'becoming' an SE/SI educator:

- How is it that you have become a sustainability/social innovation educator?

- Describe the formation of your identity or identities as such.

Your 'doing' or 'acting' in SE/SI:

- Currently, how is it that you make use of the different knowledge spaces and tools provided within and beyond your current institution to develop SE/SI?

- For instance, in preparing or delivering a SE course/resource how do you define its content?

- Do you employ already existing technologies/tools/formats/assessments, or have you created ad hoc ones?

- How do you define the content of the above activities? How much use do you make of cross-fertilisation between your own discipline and others?

Your 'being' in SE/SI: 
- How do you make use of other spaces, tools, ways of thinking or acting which mark a difference between you and any other type of educator? For example, how do you manage your own learning/research agenda in ways which you think are different to other educators?

- How do we know that SE/SI is making a difference in ourselves and others?

- How do you link SE/SI with your own personal values?

\section{Many thanks for your time!}

Open Access This article is licensed under a Creative Commons Attribution 4.0 International License, which permits use, sharing, adaptation, distribution and reproduction in any medium or format, as long as you give appropriate credit to the original author(s) and the source, provide a link to the Creative Commons licence, and indicate if changes were made. The images or other third party material in this article are included in the article's Creative Commons licence, unless indicated otherwise in a credit line to the material. If material is not included in the article's Creative Commons licence and your intended use is not permitted by statutory regulation or exceeds the permitted use, you will need to obtain permission directly from the copyright holder. To view a copy of this licence, visit http://creativecommons.org/licenses/by/4.0/.

\section{References}

Alcaraz JM, Thiruvattal E (2010) An interview with Manuel Escudero on United Nations' principles for responsible management education: a global call for sustainability. Acad Manag Learn Educ 9(3):542550. https://doi.org/10.5465/amle.9.3.zqr542

Amabile T (1983) The social psychology of creativity: a componential conceptualisation. J Pers Soc Psychol 45(2):357-376

Amabile T (1998) How to kill creativity. Harvard Business Review, September-October: 77-87

Aragon-Correa JA, Marcus AA, Rivera JE, Kenworthy AL (2017) Sustainability management teaching resources and the challenge of balancing planet, people, and profits. Acad Manag Learn Educ 16(3):469-483. https://doi.org/10.5465/amle.2017.0180

Barron F (1968) Creativity and personal freedom. Van Nostrand Company Inc, London

Brower HH (2011) Sustainable sevelopment through service learning: a pedagogical framework and case example in a third world context. Acad Manag Learn Educ 10(1):58-76. https://doi.org/10.5465 /amle.2011.59513273

Burchell J, Kennedy S, Murray A (2015) Responsible management education in UK business schools: critically examining the role of the United Nations principles for responsible management education as a driver for change. Manag Learn 46(4):479-497. https://doi.org/10.1177/1350507614549117

Checkland P (1981) Systems thinking, systems practice. Wiley, Chichester, England

Córdoba-Pachón JR (2011) Abstracting and engaging: two modes of systems thinking education. INFORMS Trans Educ 12(1):43-54. https://doi.org/10.1287/ited.1110.0072

Córdoba-Pachón JR (2019) Managing creativity: a systems thinking journey. Routledge, London

Córdoba-Pachón JR (2020a). Creativity in management education: a systemic rediscovery. Palgrave-Macmillan (pivot series), London, forthcoming

Córdoba-Pachón JR (2020b) Rich picture: a systems thinking technique to studying creativity. In Stierand M and Dorfler V (eds) handbook of research methods in creativity. Edward Elgar, London, forthcoming

Craft A (2001) Little c creativity. In: Craft A, Jeffrey B, Leibling M (eds) Creativity in education. Continuum, London, pp 45-51

Cropley D, Cropley A (2016) Promoting creativity through assessment: a formative computer-assisted assessment tool for teachers. Educ Technol 56(6):17-24

Csikszentmihalyi M (1988) Society, culture and person: a systems view of creativity. In: Csikszentmihalyi M (ed) The systems model of creativity: the collected works of Mihaly Csikszentmihalyi. Springer, New York, pp 47-61

Csikszentmihalyi M (1996) Creativity: flow and the psychology of discovery and invention. Harper Collins, New York 
Csikszentmihalyi M (1999) Implications of a systems perspective for the study of creativity. In: Sternberg R (ed) Handbook of creativity. Cambridge University Press, Cambridge (UK), pp 313-335

Csikszentmihalyi M, Wolfe R (2000) New conceptions and research approaches to creativity: implications of a systems perspective on creativity education. In: Heller KA, Monks FJ, Sternberg R, Subotnik R (eds) International handbook of giftedness and talent. Elsevier, London, pp 81-93

Dieleman H, Huisingh D (2006) Games by which to learn and teach about sustainable development: exploring the relevance of games and experiential learning for sustainability. J Clean Prod 14(9):837-847. https://doi. org/10.1016/j.jclepro.2005.11.031

Domask JJ (2007) Achieving goals in higher education: an experiential approach to sustainability studies. Int J Sustain High Educ 8(1):53-68. https://doi.org/10.1108/14676370710717599

Eisenhardt KM (1989) Building theories from case study research. Acad Manag Rev 14(4):532-550 http://www. jstor.org/stable/258557

Gangadharbatla H (2010) Technology component: a modified systems approach to creative thought. Creat Res J 22(2):219-227

Ghosal S (2005) Bad management theories are destroying good management practices. Acad Manag Learn Educ 4(1):75-91. https://doi.org/10.5465/amle.2005.16132558

Gitsham M (2012) Experiential learning for leadership and sustainability at IBM and HSBC. J Manag Dev 31(3): 298-307. https://doi.org/10.1108/02621711211208925

Glavenau V (2010) Paradigms in the study of creativity: introducing the perspective of cultural psychology. New Ideas Psychol 28(1):79-93. https://doi.org/10.1016/j.newideapsych.2009.07.007

Glavenau V, Hanson MH, Baer J, Clapp E et al (2019) Advancing creativity theory and research: a socio-cultural manifesto. Creat Behav 0(0):1-5

Hanson MH (2013) Author, self, monster: using Foucault to examine functions of creativity. J Theor Philos Psychol 33(1):18-31

Kaufman J, Beghetto R (2009) Beyond big and little: the four C model of creativity. Rev Gen Psychol 13(1):112

Kurucz EC, Colbert BA, Marcus J (2013) Sustainability as a provocation to rethink management education: building a progressive educative practice. Manag Learn 45(4):437-457. https://doi.org/10.1177 /1350507613486421

Lozano R (2006) Incorporation and institutionalization of SD into universities: breaking through barriers to change. J Clean Prod 14(9-11):787-796. https://doi.org/10.1016/j.jclepro.2005.12.010

Millar J, Price M (2018) Imagining management education: a critique of the contribution of the United Nations PRME to critical reflexivity and rethinking management education. Manag Learn 49(3):346-362

Monk A, Howard S (1998) The rich picture: a tool for reasoning about work context. Interactions 5(2):21-30

Montuori A, Purser R (1995) Deconstructing the lone genius myth: toward a contextual view of creativity. J Humanist Psychol 35(3):69-112

Moon J, Matten D (2004) Corporate social responsibility education in Europe. J Bus Ethics 54:323-337

Pol E, Ville S (2009) Social innovation: buzz or enduring term? J Socio-Econ 38:878-885. https://doi. org/10.1016/j.socec.2009.02.011

Reason P (2007) Education for ecology: science, aesthetics, Spirit and ceremony. Manag Learn 38(1):27-44. https://doi.org/10.1177/1350507607073021

Rubin A, Babbie E (1993) The logic of sampling. In: Adams P (ed) Research methods for social work. Brooks/ Cole, Pacific Grove, California, pp 367-371

Runco M, Jaeger G (2012) The standard definition of creativity. Creat Res J 24(1):92-96

Sawyer K (2006) Explaining creativity: the science of human innovation. Oxford University Press, Oxford (UK)

Sheu SJ, Wei IL, Chen CH, Yu S, Tang FI (2008) Using snowball sampling method with nurses to understand medication administration errors. J Clin Nurs 18(4):559-569. https://doi.org/10.1111/j.13652702.2007.02048.x

Smith IH, Woodworth WP (2012) Developing social entrepreneurs and social innovators: a social identity and self-efficacy approach. Acad Manag Learn Educ 11(3):390-407. https://doi.org/10.5465/amle.2011.0016

Stanton NA, McIlroy RC (2012) Designing mission communication planning: the role of rich pictures and cognitive work analysis. Theor Issues Ergon Sci 13(2):146-168. https://doi.org/10.1080/1463922 X.2010.497197

Sternberg RJ (2010) Teaching for creativity. In: Beghetto RA, Kaufman JC (eds) Nurturing creativity in the classroom. Cambridge University Press, Cambridge (UK), pp 394-414. https://doi.org/10.1017 /CBO9780511781629.020

Stierand M, Dörfler V, MacBryde J (2014) Creativity and innovation in haute cuisine: towards a systemic model. Creat Innov Haute Cuis 23(1):15-27

Tomkins L, Ulus E (2016) 'Oh, was that experiential learning?!' Spaces, synergies and surprises with Kolb's learning cycle. Manag Learn 47(2):158-178. https://doi.org/10.1177/1350507615587451 
Wagner T (2015) Creating innovators: the making of young people who will change the world. Simon \& Schuster Children's Publishing, the US

Yin RK (1994) Case Study Research. Sage publications, thousand oaks, California (the US)

Zorio-Grima A (2018) Driving factors for having visibility of sustainability contents in university degree titles. J Clean Prod. https://doi.org/10.1016/j.jclepro.2018.10.344

Publisher's Note Springer Nature remains neutral with regard to jurisdictional claims in published maps and institutional affiliations.

\section{Affiliations}

\section{José-Rodrigo Córdoba-Pachón ${ }^{1} \cdot$ Francesca Mapelli $^{2} \cdot$ Farah Nabil Adel Al Taji $^{2}$ • Diana M Donovan ${ }^{3}$}

1 School of Business and Management, Royal Holloway, University of London, Egham, England

2 Department of Management, Economics \& Industrial Engineering, Politecnico di Milano, Milan, Italy

3 School of Biological Sciences, Royal Holloway, University of London, Egham, England 